Jurnal Ilmiah Ibnu Sina, 6(2), Oktober 2021, 331-340

p-ISSN: 2502-647X; e-ISSN: 2503-1902

\title{
ANALISIS HUBUNGAN KEPATUHAN PENGOBATAN TERHADAP KONTROL GLIKEMIK PASIEN DIABETES MELITUS TIPE 2 DI INSTALASI RAWAT JALAN RUMAH SAKIT "X" BULELENG
}

\author{
I Gusti Ayu Indira Ardeliani, Pande Made Desy Ratnasari*, Agustina Nila \\ Yuliawati
}

Program Studi Sarjana Farmasi, Sekolah Tinggi Farmasi Mahaganesha ${ }^{1}$

Email $^{*}$ : desypandemade@gmail.com

Artikel diterima: 24 Agustus 2021; Disetujui: 27 September 2021

DOI: https://doi.org/10.36387/jiis.v6i2.739

\begin{abstract}
ABSTRAK
Diabetes Melitus (DM) tipe 2 merupakan penyakit kronik yang membutuhkan terapi jangka panjang. Dalam perjalanannya dijumpai permasalahan terkait kepatuhan pengobatan antidiabetik. Kepatuhan pengobatan secara langsung berpengaruh terhadap kadar glukosa darah pasien. Tujuan penelitian yaitu menganalisis hubungan kepatuhan pengobatan dengan kontrol glikemik pasien DM tipe 2.

Jenis penelitian adalah observasional dengan rancangan cross sectional yang melibatkan 90 pasien DM tipe 2 di Instalasi Rawat Jalan Rumah Sakit Umum (RSU) "X" Buleleng periode Juli-September 2020. Kriteria inklusi meliputi pasien DM tipe 2 berusia $\geq 18$ tahun, memperoleh antidiabetik yang sama minimal selama 3 bulan sebelum penelitian dilakukan, menandatangani informed consent, bersedia mengisi kuesioner dan data rekam medik lengkap. Kriteria eksklusi, yaitu kondisi umum pasien lemah atau tidak kooperatif, hamil atau menyusui. Pengambilan data melalui pemberian kuesioner Probabilistic Medication Adherence Scale (ProMAS) dan rekam medik pasien. Analisis data menggunakan uji statistik Kruskall Wallis.

Hasil penelitian menunjukkan sebagian besar 55,6\% pasien berjenis kelamin laki-laki, berumur 46-65 tahun $(61,1 \%)$, berpendidikan SD $(37,8 \%)$, mengidap DM selama 5-10 tahun (46,7\%), dengan penyakit penyerta (50\%) dan tanpa komplikasi $(77,8 \%)$. Mayoritas $(42,2 \%)$ pasien menunjukkan kepatuhan pengobatan sedangtinggi dan memiliki kontrol glikemik yang tidak terkendali (66,7\%). Hasil uji statistika menunjukkan tidak terdapat hubungan antara kepatuhan pengobatan dengan kontrol glikemik pasien $(\mathrm{p}=0,168)$. Walaupun demikian, pada hasil tampak bahwa tingkat kepatuhan berdampak pada kontrol glikemik. Pasien DM tipe 2 dengan kepatuhan tinggi menunjukkan kontrol glikemik yang lebih baik.
\end{abstract}

Kata kunci: Diabetes melitus tipe 2, kepatuhan pengobatan, kontrol glikemik

\section{ABSTRACT}

Type 2 Diabetes mellitus (T2DM) is a chronic disease that requires longterm treatment. There were problems related to antidiabetic medication adherence. 
Jurnal Ilmiah Ibnu Sina, 6(2), Oktober 2021, 331-340

p-ISSN: 2502-647X; e-ISSN: 2503-1902

Medication adherence directly affects patient's blood glucose level. The aim of this study was to analyze the association between the medication adherence and glycemic control among T2DM patients.

The study was an observational with cross sectional design. Participants were 90 of T2DM outpatient at " $X$ " Buleleng General Hospital in July-September 2020. T2DM patients were included if age $\geq 18$ years, received the same antidiabetic for three months before the study, sign informed consent, fill out the questionnare and have fully medical record data. Patient are excluded if having weak general condition, were pregnant or breastfeeding. Data was collected through interview using the Probabilistic Medication Adherence Scale (ProMAS) questionnaire and based on patient's medical records. Data were analyzed with Kruskall-Wallis test.

The results showed that most of patients were male (55.6\%), aged 46-65 years (61.1\%), had DM for 5-10 years (46.7\%), elementary school (37.8\%), with comordbidities (50\%) and without complications (77.8\%). Majority of patients $(42.2 \%)$ showed moderate-high medication adherence and the majority of patients (66.7\%) has uncontrolled blood glucose. Based on statistical tests, there was no association between medication adherence with patient's glycemic control ( $p=0.168)$. In dispite of it, finding showed that the level of medication adherence had an impact on glycemic control. Patients with high medication adherence showed better glycemic control.

Keywords: Diabetes mellitus type 2, medication adherence, glycemic control

\section{PENDAHULUAN}

Diabetes Melitus (DM) tipe 2 merupakan penyakit kronis, ditandai dengan kondisi hiperglikemia akibat terjadinya resistensi insulin (Wells dkk, 2014). Prevalensi DM tipe 2 mencapai 231,9 juta di dunia dan diprediksikan terus meningkat. Indonesia menduduki peringkat ke-7 di tahun 2018 dengan jumlah penyandang sebesar 14,4 juta jiwa dan diperkirakan meningkat di tahun 2030 dan 2045 (Kemenkes RI, 2019 dan IDF, 2019). Bali sendiri menyumbang penderita DM tipe 2 sebanyak 60.423 jiwa, yang mana
Kabupaten Buleleng menempati urutan ketiga dengan jumlah 7.322 jiwa (Dinkes Bali, 2019).

Pengendalian DM tipe 2 dilakukan dengan pemberian terapi jangka panjang guna mengontrol glukosa darah (GD), mencegah komplikasi dan perburukan penyakit (Fatimah, 2015). Keberhasilan terapi dilihat berdasarkan ketercapaian parameter GD yang meliputi HbA1c, GD puasa (GDP), GD 2 jam setelah makan dan GD sewaktu (GDS) (ADA, 2019). Studi terdahulu menunjukkan $>50 \%$ penyandang DM tipe 2 memiliki kontrol glikemik yang 
Jurnal Ilmiah Ibnu Sina, 6(2), Oktober 2021, 331-340

p-ISSN: 2502-647X; e-ISSN: 2503-1902

buruk meskipun telah menjalani pengobatan (Kamuhabwa dan kontrol GDS di Instalasi Rawat Jalan Charles, 2014; Demoz dkk, 2020)

Beberapa faktor yang mempengaruhi kontrol glikemik yaitu faktor terkait pasien, terapi, sistem kesehatan dan kepatuhan pengobatan (Nanda dkk, 2018). Kepatuhan pengobatan berperan sangat penting dalam mengontrol GD (Kassahun dkk, 2016). Penelitian sebelumnya menyebutkan bahwa rendahnya kepatuhan berimplikasi pada buruknya pengontrolan GD sehingga memicu timbulnya komplikasi, morbiditas dan mortalitas (Almadhoun dan Alagha, 2018; Alkhoshaiban dkk, 2019). Penelitian lainnya menemukan bahwa pasien yang patuh terhadap pengobatan menunjukkan penurunan GDS yang signifikan (Izzah dkk, 2013).

Kepatuhan merupakan sikap dalam mematuhi aturan penggunaan obat yang diberikan oleh tenaga kesehatan, yang menjadi salah satu aspek penting untuk mencapai keberhasilan terapi (Zeber dkk, 2013). Maka dari itu, peneliti tertarik untuk menganalisis hubungan antara kepatuhan pengobatan terhadap
Rumah Sakit “X” Buleleng.

\section{METODE PENELITIAN}

Rancangan penelitian adalah cross-sectional dengan jenis observasional. Penelitian dilakukan di Instalasi Rawat Jalan salah satu rumah sakit swasta Buleleng pada bulan September 2020. Penelitian telah memperoleh persetujuan Komite Etik Sekolah Tinggi Kesehatan Bina Usada Bali (No. 011/EA/KEPK-BUB-2021) dan izin rumah sakit. Jumlah responden yang terlibat dalam penelitian ini sebanyak 90 pasien yang diperoleh dengan teknik purposive sampling. Kriteria inklusi meliputi usia $\geq 18$ tahun, memperoleh antidiabetik yang sama selama 3 bulan, menandatangani informed consent dan bersedia mengisi kuesioner. Kriteria eksklusi yaitu pasien dalam kondisi hamil, menyusui atau lemah.

Pengambilan data dilakukan dengan cara memberikan kuesioner kepatuhan yaitu Probabilistic Medication Adherence Scale (ProMAS) dan rekam medik pasien. Kuesioner ProMAS terdiri dari 18 
Jurnal Ilmiah Ibnu Sina, 6(2), Oktober 2021, 331-340

p-ISSN: 2502-647X; e-ISSN: 2503-1902

item pertanyaan yang telah divalidasi menggunakan uji face validity (>85\%). Tingkat kepatuhan dikategorikan menjadi empat yaitu rendah (0-4), sedang-rendah (5-9), sedang-tinggi (10-14) dan tinggi (518). Kontrol glikemik dilihat berdasarkan kadar GDS yang dikategorikan menjadi terkontrol $(<200 \mathrm{mg} / \mathrm{dL})$ dan tidak terkontrol $(\geq 200 \mathrm{mg} / \mathrm{dL})$. Analisis data terkait hubungan antara kepatuhan pengobatan terhadap kontrol GDS menggunakan uji Kruskall Wallis.

\section{HASIL DAN PEMBAHASAN}

Pada karakteristik demografi yang tertera pada Tabel 1, mayoritas pasien berjenis kelamin laki-laki (55,6\%) dan berusia 46-65 tahun $(61,1 \%)$. Beberapa penelitian menunjukkan, laki-laki lebih banyak mengalami DM karena tingginya lemak visceral yang menumpuk di area rongga perut, sehingga memicu terjadinya resistensi insulin (IDF, 2019 dan Nordstrom dkk, 2016). Pada usia >45 tahun mulai terjadi penurunan fungsi tubuh salah satunya yaitu berkurangnya kemampuan sel beta pankreas dalam memproduksi insulin (Azizah, 2019).

\section{Tabel 1. Karakteristik demografi}

pasien

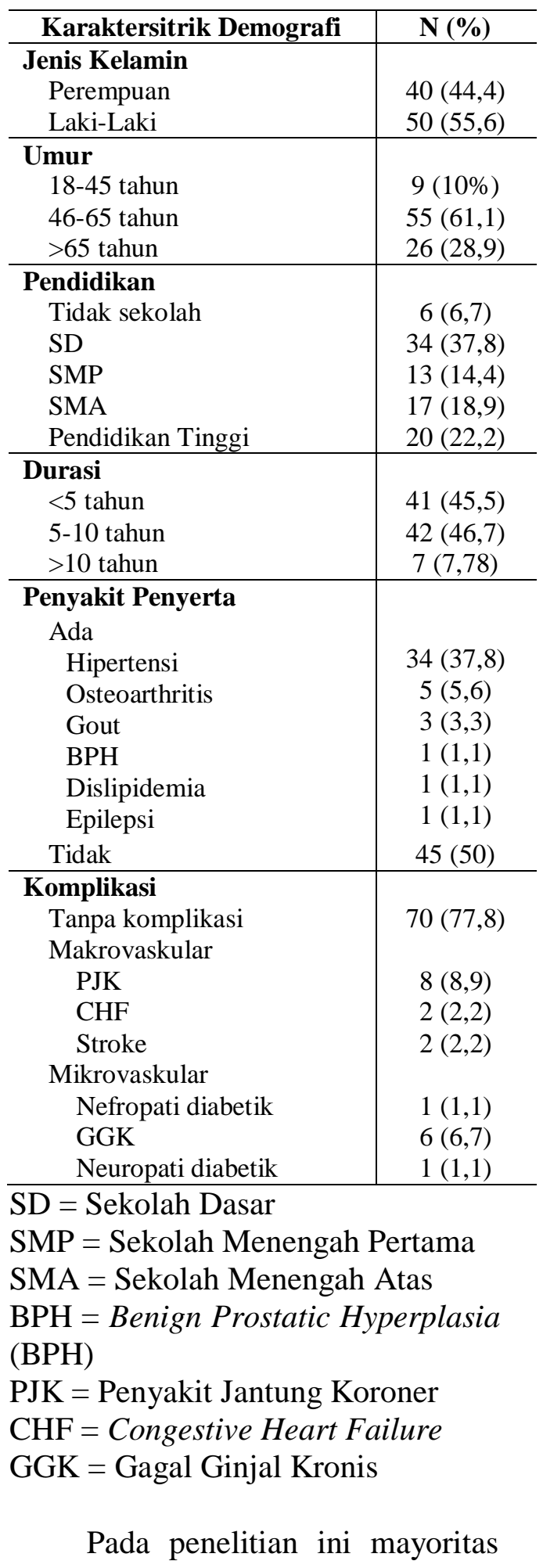


Jurnal Ilmiah Ibnu Sina, 6(2), Oktober 2021, 331-340

p-ISSN: 2502-647X; e-ISSN: 2503-1902

pasien berpendidikan $\mathrm{SD}(37,8 \%)$ dan mengalami DM selama 5-10 tahun (46,7\%). Pendidikan berkaitan dengan pengetahuan pasien terkait penyakit yang dialami sedangkan durasi penyakit berkaitan dengan risiko mengalami komplikasi (Badedi dkk, 2016; Pahlawati and Nugroho, 2019). Terkait dengan penyakit penyerta dan komplikasi, sebagian besar hipertensi (37,8\%) dan komplikasi makrovaskular $(13,3 \%)$ yaitu PJK, CHF dan stroke. Terjadinya hipertensi disebabkan oleh hiperglikemia kronik yang dapat menurunkan elastisitas pembuluh darah sedangkan komplikasi akan mempengaruhi kontrol glikemik pasien (Khangura dkk, 2018).

Tabel 2. Gambaran tingkat kepatuhan

\begin{tabular}{l|c}
\hline \multicolumn{1}{c|}{ Kategori } & $\mathbf{N}(\boldsymbol{\%})$ \\
\hline Rendah $(0-4)$ & $1(1,1 \%)$ \\
Sedang-rendah (5-9) & $15(16,7 \%)$ \\
Sedang-tinggi (10-14) & $38(42,2 \%)$ \\
Tinggi (15-18) & $36(40 \%)$ \\
\hline \multicolumn{1}{c}{ Total } & $\mathbf{9 0 ( 1 0 0 \% )}$ \\
\hline
\end{tabular}

Pada penelitian ini mayoritas pasien memiliki tingkat kepatuhan sedang-tinggi $\quad(42,22 \%) \quad$ yang disajikan pada Tabel 2. Serupa dengan penelitian sebelumnya bahwa mayoritas pasien DM tipe 2 (>40\%) memiliki tingkat kepatuhan sedang (Pratama dkk, 2019; Romadhon dkk, 2020). Kepatuhan pengobatan memegang peranan penting dalam pengontrolan glukosa darah, yang mana hal tersebut secara tidak langsung berdampak pada peningkatan kualitas hidup (Mokolomban dkk, 2018). Faktor yang berpengaruh terhadap kepatuhan pengobatan meliputi faktor terkait terapi (kompleksitas dan efek samping), sistem pelayanan kesehatan dan karakteristik pasien (Kirkman dkk, 2015).

Tabel 3. Kontrol glikemik pasien

\begin{tabular}{l|c}
\hline Kategori GDS & $\mathbf{N}(\boldsymbol{\%})$ \\
\hline Terkontrol & $30(33,3)$ \\
Tidak terkontrol & $60(66,7)$ \\
\hline \multicolumn{1}{c}{ Total } & $\mathbf{9 0}(\mathbf{1 0 0})$ \\
\hline
\end{tabular}

Pada Tabel 3 ditampilkan bahwa sebagian besar pasien $(66,7 \%)$ memiliki GDS yang tidak terkontrol. Studi terdahulu menunjukkan bahwa lebih dari $50 \%$ penyandang DM tipe 2 di Ghana dan India memiliki kontrol glikemik yang buruk (GDS $>250 \mathrm{mg} / \mathrm{dL}$ dan $\mathrm{HbA} 1 \mathrm{c}>7 \%$ (Fiagbe dkk, 2017 dan Anusuya dkk, 2018). Faktor-faktor yang signifikan berpengaruh pada kontrol glikemik 
Jurnal Ilmiah Ibnu Sina, 6(2), Oktober 2021, 331-340

p-ISSN: 2502-647X; e-ISSN: 2503-1902

adalah karakteristik demografi yakni jenis kelamin, umur, durasi mengidap DM, dan pendidikan (Haghighatpanah dkk, 2018).

Berdasarkan uji Kruskall Wallis, diperoleh hasil yaitu tidak terdapat hubungan yang signifikan antara tingkat kepatuhan pengobatan dengan kontrol glikemik pasien $(\mathrm{p}=0,168)$. Hasil ini sejalan dengan penelitian sebelumnya, bahwa tidak ditemukan adanya hubungan antara kepatuhan pengobatan dengan ketercapaian GD (p>0,05) (Zhu dkk, 2019 dan Thuy dkk, 2021). Beberapa faktor yang berpengaruh terhadap hasil penelitian berkaitan dengan karakteristik demografi pasien yang meliputi jenis kelamin, umur, pendidikan, durasi mengidap DM, penyakit penyerta dan komplikasi.

Tabel 4. Hubungan kepatuhan pengobatan dengan kontrol glikemik

\begin{tabular}{|c|c|c|c|}
\hline \multirow{2}{*}{ Kategori } & \multicolumn{2}{|c|}{ Kontrol glikemik } & \multirow{2}{*}{$\begin{array}{l}\text { Nilai } \\
\text { p }^{*}\end{array}$} \\
\hline & $\mathbf{T}$ & TT & \\
\hline Rendah & 0 & $1,1 \%$ & \multirow{5}{*}{$\mathbf{0 , 1 6 8}$} \\
\hline $\begin{array}{l}\text { Sedang- } \\
\text { rendah }\end{array}$ & $4,4 \%$ & $12,2 \%$ & \\
\hline $\begin{array}{l}\text { Sedang- } \\
\text { tinggi }\end{array}$ & $12,2 \%$ & $2730 \%$ & \\
\hline Tinggi & $16,7 \%$ & $23,3 \%$ & \\
\hline Total & $33,3 \%$ & $66,7 \%$ & \\
\hline
\end{tabular}

$\mathrm{T}=$ Terkontrol

$\mathrm{TT}=$ Tidak Terkontrol
Banyaknya jumlah pasien dengan kepatuhan pengobatan tinggi namun memiliki kontrol glikemik yang tidak terkendali juga dapat mempengaruhi hasil. Selain itu, keterbatasan parameter glukosa darah yang digunakan, yaitu GDS dapat berpengaruh terhadap hasil kontrol glikemik pasien. Seharusnya, kontrol glikemik dilihat berdasarkan empat parameter yaitu $\mathrm{HbA1c}$, GDP, G2PP dan GDS.

Meskipun hasil menunjukkan tidak terdapat hubungan yang signifikan, namun pada Tabel 4 terlihat bahwa tingkat kepatuhan mempengaruhi kontrol glikemik. Pasien dengan GD yang terkontrol menunjukkan tingkat kepatuhan tinggi $(16,7 \%)$. Hasil ini sejalan dengan beberapa penelitian yang menemukan bahwa tingkat kepatuhan berpengaruh terhadap terkontrolnya glukosa darah (Zamaa dan Sainudin, 2019; Zulfi dan Muflihatin, 2020). Studi menyebutkan bahwa semakin tinggi tingkat kepatuhan pasien terhadap pengobatannya, maka semakin baik kontrol glikemik yang dimiliki, begitu pula sebaliknya semakin rendah kepatuhan terhadap 
Jurnal Ilmiah Ibnu Sina, 6(2), Oktober 2021, 331-340

p-ISSN: 2502-647X; e-ISSN: 2503-1902

pengobatannya maka semakin buruk

pula kontrol glikemik yang dihasilkan

(Chawla dan Jaggi, 2016; Romadhon

dkk, 2020).

Selain kepatuhan pengobatan, kepatuhan lainnya dapat mempengaruhi kontrol glikemik antara lain kepatuhan diet, melakukan aktivitas fisik dan kontrol rutin ke pelayanan kesehatan (Hamarno dkk 2016; Widodo, 2017). Kepatuhan diet berkaitan dengan ketaatan pasien terhadap jenis dan jumlah asupan makanan, minuman yang dikonsumsi. Kepatuhan melakukan aktivitas fisik yang dimaksud adalah ketaatan pasien dalam melaksanakan aktivitas harian seperti berolahraga dan latihan jasmani 3-4 kali tiap minggu. Pola diet dan rutin dalam beraktivitas berdampak pada kontrol glikemik pasien yang baik (Widodo, 2017).

Kepatuhan kontrol rutin ke pelayanan kesehatan merupakan ketaatan pasien dalam melakukan pemeriksaan terkait penyakit yang diderita. Pasien yang patuh cenderung mendapatkan pehamanan dan informasi terkait pengendalian GD yang baik dengan pengobatan maupun perubahan gaya hidup serta informasi mengenai perkembangan penyakit yang dialami (Hamarno dkk, 2016).

\section{KESIMPULAN}

Pasien DM tipe 2 di Instalasi Rawat Jalan Rumah Sakit Umum "X" Buleleng mayoritas berjenis kelamin laki-laki (55,6\%), berumur 46-65 tahun $(61,1 \%)$, berpendidikan SD (37,8\%), mengidap DM selama 5-10 tahun $(46,7 \%)$, memiliki penyakit penyerta $(50 \%)$ dan tidak mengalami komplikasi (77,8\%). Hasil uji menunjukkan tidak terdapat hubungan antara kepatuhan pengobatan dengan kontrol glikemik pasien $(\mathrm{p}=0,168)$, namun pada hasil tampak bahwa tingkat kepatuhan berdampak pada kontrol glikemik. Pasien yang memiliki kepatuhan tinggi menunjukkan kontrol glikemik yang lebih baik.

\section{UCAPAN TERIMA KASIH}

Peneliti mengucapkan terima kasih kepada semua pihak yang terlibat serta membantu jalannya penelitian. 
Jurnal Ilmiah Ibnu Sina, 6(2), Oktober 2021, 331-340

p-ISSN: 2502-647X; e-ISSN: 2503-1902

\section{DAFTAR PUSTAKA}

American Diabetes Association (ADA), 2019, Standars of Medical Care in Diabetes, Diabetes Care Journal, 42(Suppl. 1), S75-76.

Alkhoshaiban A, Hassan Y, Loganathan M, 2019, Type II Diabetic Patients: Satisfaction, Medication Adherence, and Glycemic Control After The Application of Pharmacist Counseling Program, Archives Of Pharmacy Practice, 10(4), 127-136.

Almadhoun M, Alagha A, 2018, Assessment of Medication Adherence And Its Association With Glycemic Control Among Type-2 Diabetes Mellitus Patients in Gaza-Palestine, Clinical And Experimental Pharmacology. 10

Anusuya GS, Ravi R, Gopalakrishnan S, 2018, Prevalence of Undiagnosed and Uncontrolled Diabetes Mellitus Among Adults in South Chennai, International Journal of Communitiy Medicine and Public Health, 5(12), 52005204.

Azizah MI, 2019, Penyakit Mitokondria: Review Penyakit Mitokondria, Review, December.

Badedi M, Solan Y, Darraj H, 2016. Factors Associated with LongTerm Control of Type 2 Diabetes Mellitus, Journal of Diabetes Research.
Chawla A, Chawla R, Jaggi S, 2016. Microvasular and Macrovascular Complications In Diabetes Mellitus: Distinct or Continuum?, Indian Journal of Endocrinology and Metabolic, 20(4), 546-551.

Demoz GT, Wahdey S, Bahrey D, 2020, Predictors of Poor Adherence to Antidiabetic Therapy in Patients with Type 2 Diabetes: A Cross-Sectional Study Insight from Ethiopia, Diabetology And Metabolic Syndrome, 12(1), 1-8.

Dinas Kesehatan Provinsi (Dinkes) Bali, 2019, Profil Kesehatan Provinsi Bali, Dinas Kesehatan Provinsi Bali, Denpasar.

Fatimah RN, 2015, Diabetes Melitus Tipe 2, J Majority, 4(5), 93101.

Fiagbe J, Bosoka S, Opong J, 2017, Prevalence of Controlled and Uncontrolled Diabetes Mellitus and Associated Factors of Controlled Diabetes Among Diabetic Adults in The Hohoe Municipality of Ghana, Diabetes Management, 7(5), 343-354.

Garcia-Pérez LE, Álvarez M, Dilla T, 2013, Adherence To Therapies in Patients with Type 2 Diabetes, Diabetes Therapy, 4(2), 175-194.

Haghighatpanah M, Sasan, Amir, 2018, Osong Public Health and Research Perspectives Factors That Correlate with Poor Glycemic Control in Type 2 Diabetes Mellitus Patients with Complications, Osong Public 
Jurnal Ilmiah Ibnu Sina, 6(2), Oktober 2021, 331-340

p-ISSN: 2502-647X; e-ISSN: 2503-1902

Health and Research

Perspectives, 9(4), 167-174.

Hamarno R, Nurdiansyah M, Toyibah

A, 2016, Hubungan Antara

Kepatuhan Kontrol Dengan

Terjadinya Komplikasi Kronis

Pada Penderita Diabetes

Melitus Tipe 2 Di Puskesmas

Janti Kota Malang, Jurnal

Keperawatan, 7(2), 126-134.

International Diabetes Federation, 2019, IDF Diabetes Atlas, International Diabetes Federation, Brussels.

Izzah Z, Suprapti B, Aryani T, 2013. Diabetes Support Groups Improve Patient's Compliance and Control Blood Glucose Levels, Indonesian Journal of Clinical Pharmacy, 2(3), 94101.

Kamuhabwa AR, Charles E, 2014, Predictors of Poor Glycemic Control in Type 2 Diabetic Patients Attending Public Hospitals in Dar Es Salaam, Drug, Healthcare And Patient Safety, 6, 155-165.

Kassahun T, Eshetie T, Gesesew H, 2016, Factors Associated with Glycemic Control Among Adult Patients with Type 2 Diabetes Mellitus: A CrossSectional Survey in Ethiopia Endocrine Disorders, $B M C$ Research Notes, 9, 1-6.

Kementerian Kesehatan Republik Indonesia (Kemenkes), 2019, Profil Kesehatan Indonesia 2018, Indonesia Health Profile 2018, Jakarta.

Khangura D, Kurukulasuriya LR, Connell AW, 2018, Diabetes
And Hypertension: Clinical Update, American Journal of Hypertension, 31(5), 1-7.

Kirkman M, Rowan MT, Levin R, 2015, Determinants of Adherence to Diabetes Medications: Findings from A Large Pharmacy Claims Database, Diabetes Care, 1-6.

Mokolomban C, Wiyono W, Mpila D, 2018, Kepatuhan Minum Obat Pada Pasien Diabetes Melitus Tipe 2 Disertai Hipertensi Dengan Menggunakan Metode MMAS-8, Pharmacon Jurnal Ilmiah Farmasi, 7(4), 69-78.

Nanda OD, Wiryanto B, Triyono EA, 2018, Hubungan Kepatuhan Minum Obat Anti Diabetik dengan Regulasi Kadar Gula Darah pada Pasien Perempuan Diabetes Mellitus, Amerta Nutrition, 2(4), 340-348.

Nordström A, Hadrévi J, Olsson T, 2016, Higher Prevalence of Type 2 Diabetes in Men Than in Women is Associated with Differences In Visceral Fat Mass. Journal of Clinical Endocrinology and Metabolism, 101(10), 37403746.

Pahlawati A, Nugroho PS, 2019, Hubungan Tingkat Pendidikan Dan Usia Dengan Kejadian Diabetes Melitus Di Wilayah Kerja Puskesmas Palaran Kota Samarinda Tahun 2019, Borneo Student Research Bsr, 1(1), 15.

Pratama IPY, Andayani TM, Kristina SA, 2019, Knowledge, Adherence and Quality of Life 
Jurnal Ilmiah Ibnu Sina, 6(2), Oktober 2021, 331-340

p-ISSN: 2502-647X; e-ISSN: 2503-1902

Among Type 2 Diabetes Mellitus Patients, International Research Journal of Pharmacy, 10(4), 52-55.

Romadhon R, Saibi Y, Nasir N. 2020. Kepatuhan Terhadap

Pengobatan Pasien Diabetes Melitus Tipe 2 Di Puskesmas Jakarta Timur, Jurnal Farmasi Galenika, 6(1), 94-103.

Thuy LQ, Thi H, Nam P, 2021 Factors Associated with Glycaemic Control Among Diabetic Patients Managed at An Urban Hospital in Hanoi Vietnam, Hindawi Publishing Corporation. 1-6.

Wells B.G, DiPiro J.T, Schwinghammer T.L, 2014, Pharmacotherapy Handbook, $9^{\text {th }}$ edition, Mcgraw-Hill Education.

Widodo HAP, 2017, Hubungan Antara Kepatuhan Diet Dengan Perubahan Kadar Gula Darah Pada Pasien Diabetes Melitus Yang Berobat Ke Puskesmas Tawangrejo Kota Madiun, Skripsi, Prodi Keperawatan Stikes Bhakti Husada Mulia Madiun.

Zamaa M, Sainudin, S, 2019, Hubungan Kepatuhan Pengobatan dengan Kadar Gula Darah Sewaktu Pada Pasien Diabetes Melitus Tipe II, Jambura Nursing Journal, 1(1), 11-18.

Zeber JE, Manias E, Williams AF, 2013, A systematic literature review of psychosocial and behavioral factors associated with initial medication adherence: A report of the
ISPOR medication adherence \& persistence special interest group, Value in Health, 16(5), 891-900.

Zhu H, Yu M, Hu H, 2019, Factors associated with glycemic control in community-dwelling elderly individuals with type 2 diabetes mellitus in Zhejiang, China: a cross-sectional study, BMC Endocrine Disorders, 19(57), 1-11.

Zulfi H, Muflihatin S, 2020. Hubungan Kepatuhan Minum Obat dengan Terkendalinya Kadar Gula Darah pada Pasien DM Tipe II di Irna RSUD Abdul Wahab Sjahranie Samarinda, Borneo Student Research (BSR), 1(3), 16791686. 